\title{
A perspectiva dos professores numa formação em Estatística
}

The perspective of teachers in a statistics teacher education

\author{
Bruna Rodrigues ${ }^{1}$ \\ João Pedro Mendes da Ponte ${ }^{2}$
}

\section{Resumo}

Este estudo enquadra-se numa experiência de formação que articula conhecimentos de conteúdo e de didática da Estatística, no âmbito de um curso de especialização para professores de Matemática do ensino básico. O nosso objetivo é identificar os conhecimentos desenvolvidos pelos participantes sobre o ensino da Estatística, de modo a saber como percepcionam este processo formativo. Os dados foram coletados através de questionários, relatórios, gravações de áudio e vídeo, além de um diário de bordo, no qual analisamos o trabalho e o balanço realizado pelos participantes. Concluímos que este processo formativo teve impacto no desenvolvimento profissional dos professores no que diz respeito à valorização da abordagem exploratória da Estatística, nomeadamente na realização de investigações no contexto escolar.

Palavras-chave: Ensino da Estatística; Formação de Professores; Desenvolvimento profissional; Investigação estatística.

\section{Abstract}

This study is part of a teacher education experience that articulates knowledge of content and didactics of statistics, carried out in a specialization course for mathematics teachers of basic education. Our objective is to identify the knowledge developed by participants about the teaching of statistics and to know how they perceive this teacher education process. Data was collected through questionnaires, reports, audio and video recordings, as well as a logbook, where we analyzed the participants' work and evaluation of the course. We conclude that this teacher education process had an impact on the professional development of the teachers regarding the valorization of the exploratory approach to statistics, namely in carrying out investigations in the school context.

Keywords: Statistics Education; Teacher education; Professional development; Statistical investigation.

\footnotetext{
${ }^{1}$ Instituto de Educação, Universidade de Lisboa | brunaa-rodrigues@hotmail.com

${ }^{2}$ Instituto de Educação, Universidade de Lisboa | jpponte@ie.ulisboa.pt
} 


\section{Introdução}

A literacia estatística é necessária para lidar com as informações do cotidiano, assim como com questões relacionadas ao trabalho. Para Martins e Ponte (2011), a literacia reporta-se a um conjunto de princípios, ideias, aptidões e capacidades de comunicação necessário para que as pessoas possam tratar, com eficiência, casos que envolvam dados de cariz qualitativo e quantitativo que lhes surgem durante a vida e em situações profissionais. O desenvolvimento da literacia estatística é um objetivo fundamental no ensino da Estatística (FRANKLIN ET AL., 2005), mas esta literacia não é promovida quando o ensino da Estatística é centrado no uso de fórmulas e cálculos sem relação com dados reais, sem promover a formação de cidadãos críticos, capazes de lidar adequadamente com os dados que os rodeiam. Em contrapartida, um processo de ensino e aprendizagem que envolva tarefas de cunho exploratório - com o uso de investigações estatísticas e recursos tecnológicos - possibilita o processo de desenvolvimento da literacia estatística. Para Santos e Branches (2019), uma simples leitura de um gráfico deve ser apoiada pela literacia estatística.

Os cursos de licenciatura em Matemática no Brasil habilitam o professor a lecionar nos anos finais do Ensino Fundamental e no Ensino Médio. De acordo com Costa e Nacarato (2011), estes cursos costumam propor disciplinas de Estatística genéricas com o intuito de atender a diferentes cursos simultaneamente, como os relacionados com as áreas de saúde e finanças. Assim, a gestão do currículo destas disciplinas depende mais das condições da instituição do que da real necessidade do professor em formação. Além disso, os materiais didáticos e livros-texto do ensino superior apresentam limitações relativamente ao apoio que podem dar à atividade docente. Na verdade, os materiais didáticos muitas vezes não apresentam tarefas de natureza exploratória e não impulsionam o uso dos recursos tecnológicos, e os livros-texto do ensino superior apresentam apenas os conteúdos específicos da Estatística, sem considerar os seus aspectos didáticos (LOPES, 2013). Deste modo, a prática investigativa e a presença da tecnologia, alinhadas ao propósito de desenvolver a literacia estatística dos alunos, dificilmente chegam a ser conhecidas pelos docentes com responsabilidade pelo ensino da Estatística.

Apesar dos diferentes fatores que concorrem para uma prática docente empobrecida relativamente à Estatística, os professores podem refletir e construir novos significados para este ensino. Muitos professores procuram preencher as lacunas existentes na sua formação inicial através de cursos de aperfeiçoamento ou de especialização. Para Day (2001), os cursos de formação contínua, independentemente da duração, desempenham um forte papel na promoção de um ensino de qualidade, visto que neles o professor pode desenvolver capacidades emocionais e intelectuais importantes para a sua prática.

Neste artigo, apresentamos uma experiência de formação que articula conhecimentos de conteúdo e de didática da Estatística num curso de especialização para professores de Matemática. No tocante à perspectiva curricular, seguimos uma abordagem de cunho exploratório (ESTEVAM ET AL., 2017; PONTE, 2005) em torno das tarefas, da comunicação e, especialmente, a realização de investigações estatísticas apoiadas por recursos tecnológicos. A dinâmica presente nas sessões visa articular situações autênticas de sala de aula com reflexões individuais e coletivas acerca do ensino da Estatística. O nosso objetivo é identificar os conhecimentos desenvolvidos pelos participantes sobre o ensino da Estatística, de modo a saber como percepcionam este processo formativo no que diz respeito à sua dinâmica e à sua estrutura curricular. 


\title{
Formação do professor para ensinar Estatística
}

\author{
Perspectivas curriculares na formação
}

A formação do professor deve atender aos diferentes aspectos relacionados à sua prática. De acordo com Ponte et al. (2012), esta prática é caracterizada por dois elementos centrais: as tarefas propostas aos alunos e a comunicação estabelecida na sala de aula.

O ensino da Estatística pode ser conduzido por diferentes tipos de tarefas. No seu ensino, o tipo de tarefa a propor ao aluno deve ter como base o tipo de aprendizagem visada. Em geral, os materiais didáticos dedicados aos conceitos estatísticos apresentam como foco os exercícios que não exigem nível cognitivo elevado. Além disso, são conduzidos pela repetição de procedimentos, sem associação clara ao desenvolvimento da literacia estatística (COUTINHO \& SPINA, 2015). Por outro lado, diferentes pesquisas apontam os benefícios existentes numa abordagem exploratória das tarefas e da comunicação a ser estabelecida na sala de aula.

A abordagem exploratória configura uma ruptura no ensino tradicional que determina que o professor é o transmissor dos conceitos e técnicas e os alunos apenas reproduzem tais conhecimentos através de tarefas que exigem apenas a repetição. Para Stein et al. (2008), uma aula exploratória estrutura-se a partir de três fases principais: a proposta da tarefa; a "exploração" realizada pelos alunos; e a fase de discussão e sistematização das aprendizagens. Na fase de exploração, os alunos constroem os seus próprios métodos para a resolução da tarefa proposta. O professor deve oferecer apoio para que os alunos tenham um papel ativo na aprendizagem, de modo que a sua interferência não reduza o grau de desafio da tarefa (STEIN \& SMITH, 1998). Além disso, o professor deve estar atento às respostas e raciocínios dos alunos para poder conduzir a discussão e sistematização das aprendizagens. Na fase de discussão e sistematização de aprendizagens, o professor seleciona as tarefas a discutir e elabora uma sequência de questões de modo que os alunos possam justificar seus raciocínios e confrontar as suas resoluções com as de seus colegas.

Ponte et al. (2017) afirmam que os professores aprendem de modo análogo ao dos alunos. Deste modo, a abordagem exploratória das tarefas e o tipo de comunicação estabelecida neste contexto podem servir de base ao trabalho na formação de professores. Assim, os professores em formação experimentam um ambiente favorável para a construção de aprendizagens de forma ativa, pelo que as reflexões coletivas ganham destaque.

Dentre as recomendações para a formação de professores que ensinam Estatística está o uso de investigações estatísticas, que, de acordo com o GAISE Report (FRANKLIN ET AL., 2005), são compostas por quatro processos principais: (i) formulação de perguntas; (ii) coleta de dados; (iii) análise de dados; e (iv) interpretação de resultados. Martins e Ponte (2011) afirmam que ao longo deste percurso é possível explorar aspectos do raciocínio estatístico, assim como conhecimentos sobre técnicas de recolha de dados e medidas estatísticas de localização, dispersão e associação, por exemplo.

No contexto escolar, esta atividade não chega para proporcionar um conhecimento estatístico sofisticado próprio dos estatísticos. No entanto, mesmo promovendo apenas conhecimentos limitados ao aluno, a investigação estatística pode ter para ele muito valor, proporcionando em todos os ciclos o desenvolvimento da noção de variabilidade (BURRIL \& BIEHLER, 2011). Quando associada aos contextos que fazem parte do cotidiano dos alunos, 
esta perspectiva pode apresentar uma relação estreita com o desenvolvimento da literacia estatística. As ferramentas tecnológicas devem ser utilizadas neste processo, visto que permitem uma construção ativa dos conhecimentos e proporcionam oportunidades de reflexão sobre os fenômenos observados, além de possibilitarem o desenvolvimento de capacidades metacognitivas (BEN-ZVI, 2000).

Para Heaton e Mickelson (2002), é importante que os professores desenvolvam a habilidade de lidar com as investigações, o que abrange a compreensão dos tipos de questões que podem ser exploradas, os tipos de dados envolvidos, bem como a constante reflexão acerca do propósito do estudo. Pelo seu lado, Goth e Xu (2011) indicam que, para que os professores sejam capazes de fazer e conduzir investigações estatísticas no contexto escolar, é necessário que eles próprios experimentem atividades desta natureza.

Apesar dos benefícios de uma formação voltada para a realização de investigações estatísticas, Henriques e Oliveira (2013) apontam que o ensino da Estatística nesta perspectiva ainda não possui ampla divulgação. As autoras indicam que a maioria dos professores não tiveram experiências de formação centradas no ciclo investigativo da Estatística, e é provável que este tipo de prática não exista em suas aulas.

\section{Formação orientada para a prática}

Um processo formativo pode tomar vários rumos distintos. Tal como indica Batanero (2002), a criação de um curso sobre o ensino de Estatística deve ter como ponto inicial a análise dos problemas de formação dos professores no que diz respeito aos seus conhecimentos do conteúdo e didático. Neste contexto, uma formação que valoriza as situações reais de sala de aula deve receber destaque.

Para Smith (2001), a formação deve estar relacionada à prática profissional. Segundo a autora, este processo formativo deve ser conduzido de maneira reflexiva a partir de diferentes atividades como a observação de episódios de sala de aula. Tal como indica Ponte (2011), a conexão com situações autênticas da sala de aula tem potencial para transformar crenças, hábitos e práticas dos professores de maneira que possam compreender e tomar decisões adequadas. Na verdade, as "situações de prática autêntica" podem servir como material de estudo na formação de professores, sendo proposto um ambiente de pesquisa e crítica a respeito das diferentes interações, comunicações e pensamentos que emergem do ambiente real da sala de aula.

A seleção adequada de tarefas a utilizar em sala de aula é de grande importância no processo de ensino e aprendizagem. Smith (2001) destaca este ponto como um forte ponto de reflexão a respeito dos objetivos a serem atingidos, bem como sobre os conhecimentos prévios e necessários aos alunos. Nesta mesma linha, ressalta a análise das respostas dos alunos a tarefas, em que estes revelam suas concepções e erros. Nesta atividade, os professores podem refletir sobre os tipos de feedback a fornecer aos alunos e sobre como estimular a reflexão dos alunos sobre seus equívocos e incompreensões, além de construir e reconstruir os significados da Matemática e de como se faz Matemática; e, acrescentamos nós, o mesmo acontece para a Estatística. Outro ponto a ser considerado, na perspectiva da autora, é o ciclo de trabalho dos professores. Os professores realizam um ciclo que começa pelo planejamento das atividades, envolve as interações na execução das atividades, e termina com a reflexão dos professores. Cada uma das fases deste ciclo envolve diversas atividades. Embora esta seja uma descrição simplificada do trabalho do professor, ela pode enfatizar as suas atividades fundamentais - que podem estar conectadas a práticas 
autênticas. Assim, os professores podem analisar as oportunidades de aprendizagem concedidas naquele ambiente observado, os conhecimentos articulados pelos alunos, as atitudes do professor, as dificuldades inerentes ao processo e, assim, refletir sobre as adaptações de abordagem e de tarefas para atingir determinado objetivo.

Como um exemplo de formação em Estatística com este princípio, destaca-se a experiência de Green e Blankenship (2013), que realizaram um curso baseado nas ideias propostas no GAISE Report (FRANKLIN ET AL., 2005), cujas ênfases eram o pensamento estatístico, a necessidade de dados e de contexto, a onipresença da variação e o papel fundamental das inferências. Além dos aspectos estatísticos salientados pelos autores, o propósito do curso visava o equilíbrio entre o conteúdo, a pedagogia e a avaliação. Os autores afirmam que, para que os participantes tivessem uma aprendizagem significativa dos conceitos e questões relacionados com o ensino e aprendizagem da Estatística, houve um encorajamento para que pudessem dirigir discussões, com destaque para a elaboração de planos de aula. A conexão entre o conteúdo, a pedagogia e a avaliação conduziram os participantes a se posicionarem como professores, e não apenas como alunos da graduação.

Na busca por uma formação orientada para a prática, surge o trabalho apresentado por Estevam, Cyrino e Oliveira (2017), no qual os autores buscaram compreender a natureza das reflexões que emergem da análise do registro de vídeo de uma aula realizada com uma turma de $9 .^{\circ}$ ano do ensino fundamental sobre as medidas de tendência central. A partir de transcrições de audiogravações das interações dos professores, os autores analisam suas reflexões sobre a aula, suas características, as ações e interações relacionadas à sessão que tinha como base o ensino exploratório da Estatística. As reflexões que os professores realizaram tiveram como base, portanto, a própria prática. Os autores concluíram que este processo formativo permitiu que os participantes pudessem compreender, contextualizar e justificar práticas de ensino de maior complexibilidade.

\section{Metodologia de investigação}

\section{A experiência de formação}

A experiência de formação ocorreu no ano letivo de 2017, num curso de especialização para professores de Matemática na Zona Oeste do Rio de Janeiro. Foi realizada no âmbito da disciplina de Estatística, no decorrer de cinco sessões, de quatro horas cada. A primeira autora deste artigo assumiu o duplo papel de investigadora e formadora. Nesta experiência foi proposto um trabalho que visava proporcionar aos professores em formação situações propiciadoras de discussão e partilha de conhecimentos relevantes para suas práticas atuais e futuras por meio da articulação entre os conteúdos estatísticos e conhecimentos didáticos para o seu ensino. A organização da experiência de formação teve por base uma análise de documentos norteadores importantes para o ensino da Matemática e da Estatística no Ensino Básico (BRASIL, 1997, 1998; NCTM, 2000; FRANKLIN ET AL., 2005). Além disso, utilizamos estudos associados à formação, para ensinar estatística, e ao desenvolvimento profissional, voltado para os contextos reais de sala de aula (DAY, 2001; SMITH, 2001). Quanto à perspectiva curricular, adotamos uma abordagem exploratória (PONTE, 2005) e a utilização de investigações estatísticas (FRANKLIN ET AL., 2005). O trabalho realizado nas diversas sessões está indicado na Tabela 1. A formação do professor deve atender aos 
diferentes aspectos relacionados à sua prática. De acordo com Ponte et al. (2012), esta prática é caracterizada por dois elementos centrais: as tarefas propostas aos alunos e a comunicação estabelecida na sala de aula.

Tabela 1: O trabalho desenvolvido na experiência de formação

\section{Trabalhos propostos aos professores Objetivos}

\begin{tabular}{|c|c|c|}
\hline $\begin{array}{l}\text { 1. }{ }^{\mathrm{a}} \text { sessão } \\
\text { (4 horas) }\end{array}$ & $\begin{array}{l}\text { Análise de orientações curriculares e de } \\
\text { tarefas presentes em manuais do ensino } \\
\text { básico para o ensino da Estatística. }\end{array}$ & $\begin{array}{l}\text { - Discutir o conceito de literacia estatística a } \\
\text { partir da discussão dos documentos } \\
\text { curriculares; } \\
\text { - Promover a reflexão sobre em que medida } \\
\text { a literacia estatística pode ser evidenciada nas } \\
\text { tarefas sugeridas nos materiais escolares. }\end{array}$ \\
\hline $\begin{array}{l}\text { 2. }{ }^{a} \text { sessão } \\
\text { (4 horas) }\end{array}$ & $\begin{array}{l}\text { - Realização de tarefas que envolvam a } \\
\text { análise de gráficos e tabelas, } \\
\text { nomeadamente em situações em que as } \\
\text { representações tenham sido } \\
\text { manipuladas e contenham erros; } \\
\text { - Observação e reflexão sobre } \\
\text { documentos de sala de aula, onde os } \\
\text { alunos respondem as tarefas } \\
\text { anteriormente propostas aos professores; } \\
\text { - Seleção de tarefas que favoreçam o } \\
\text { desenvolvimento da literacia para propor } \\
\text { aos seus alunos; a realizar com os seus } \\
\text { próprios alunos. }\end{array}$ & $\begin{array}{l}\text { - Promover a reflexão sobre os tipos de } \\
\text { tarefa que podem auxiliar no desenvolvimento } \\
\text { da literacia estatística; } \\
\text { - Promover a reflexão sobre os } \\
\text { pensamentos que os alunos evidenciam na } \\
\text { execução das tarefas; } \\
\text { - Promover a reflexão sobre eventuais erros } \\
\text { e equívocos que os alunos cometem como uma } \\
\text { oportunidade para promover a aprendizagem. }\end{array}$ \\
\hline $\begin{array}{l}\text { 3. }{ }^{\text {a sessão }} \\
\text { (4 horas) }\end{array}$ & $\begin{array}{l}\text { - Realização de tarefas que envolvam } \\
\text { medidas estatísticas com o uso de } \\
\text { recursos tecnológicos; } \\
\text { - Discussão sobre o papel da } \\
\text { tecnologia no ensino da Estatística. }\end{array}$ & $\begin{array}{l}\text { - Desenvolver o conhecimento de conteúdo } \\
\text { sobre as medidas estatísticas dos professores; } \\
\text { - Desenvolver a habilidade dos professores } \\
\text { em tratar dados a partir de recursos } \\
\text { computacionais; } \\
\text { - Desenvolver a reflexão sobre as } \\
\text { potencialidades do uso da tecnologia no ensino } \\
\text { da Estatística. }\end{array}$ \\
\hline $\begin{array}{l}\text { 4. }{ }^{\text {a }} \text { sessão } \\
\text { (4 horas) }\end{array}$ & $\begin{array}{l}\text { - Realização de uma mini-investigação } \\
\text { estatística com os professores; } \\
\text { Reflexão sobre a investigação realizada e } \\
\text { sobre os elementos estatísticos utilizados } \\
\text { na sua condução; } \\
\text { - Planificação de uma investigação } \\
\text { estatística a realizar com os seus alunos. }\end{array}$ & $\begin{array}{l}\text { - Desenvolver o raciocínio inferencial informal } \\
\text { dos professores e articular diferentes elementos } \\
\text { da Estatística a partir das investigações; } \\
\text { - Promover o reconhecimento das } \\
\text { investigações como um tipo de tarefa que } \\
\text { articula diferentes conhecimentos estatísticos. }\end{array}$ \\
\hline $\begin{array}{l}\text { 5. }{ }^{a} \text { sessão } \\
\text { (4 horas) }\end{array}$ & $\begin{array}{l}\text { - Discussão sobre as investigações } \\
\text { realizadas entre os grupos; } \\
\text { - Aplicação de um questionário final. }\end{array}$ & $\begin{array}{l}\text { - Desenvolver a percepção dos professores } \\
\text { sobre como os alunos se desenvolvem ao } \\
\text { longo de uma investigação; } \\
\text { - Promover o reconhecimento das } \\
\text { investigações como um tipo de tarefa capaz de } \\
\text { desenvolver a literacia estatística dos seus } \\
\text { alunos. }\end{array}$ \\
\hline
\end{tabular}

Fonte: Os autores. 
Um aspecto transversal na formação foi a utilização de contextos reais de sala de aula como um recurso didático. Isto é, buscamos estabelecer uma formação orientada para a prática de modo a promover reflexões e discussões acerca da seleção e aplicação de tarefas, bem como previsão de respostas dos alunos e da análise dessas respostas. De acordo Cobb et al. (2003), numa experiência, as tarefas a serem propostas devem estar associadas à conjectura subjacente ao tipo de experiência. Assim, incluímos tarefas que possibilitavam o desenvolvimento do conhecimento do significado dos conceitos estatísticos de modo a desenvolver a literacia estatística dos alunos.

\section{Participantes}

O grupo participante desta experiência de formação era composto por 13 professores, dos quais alguns lecionavam no Ensino Fundamental, especialmente no $2 .^{\circ}$ ciclo (6. a 9. anos), e outros não exerciam atualmente a profissão ${ }^{3}$. Os professores atuavam, prioritariamente, na Zona Oeste do Rio de Janeiro e optaram por cursar a pós-graduação com o objetivo de aperfeiçoar seus conhecimentos para a sua prática docente. Todos os participantes já tinham tido, ao longo da graduação, disciplinas relativas ao estudo da Estatística. No entanto, com a sua participação neste curso, pretendiam promover o aperfeiçoamento do conhecimento que já possuíam, especialmente por ser um assunto que geralmente é abordado numa única disciplina do curso de graduação. Todos referiram que ao longo da formação não tiveram experiências com investigações estatísticas e nem com a abordagem exploratória.

\section{Recolha e análise de dados}

Esta investigação assume uma natureza qualitativa e interpretativa (ERICKSON, 1986). Os dados foram recolhidos pela observação participante com elaboração de um diário de bordo (DB), gravação do áudio das sessões (S1 - S5), um questionário final sobre a Estatística e a didática da Estatística (QF) e um relatório sobre o curso (R).

Os dados foram analisados de modo a reconhecer no discurso dos participantes as suas percepções acerca da experiência formativa, precisamente no tocante à perspectiva curricular adotada, nomeadamente em relação: (i) à análise dos materiais didáticos e das orientações curriculares; (ii) à abordagem exploratória das tarefas; e (iii) ao uso das investigações estatísticas. No segundo momento, analisamos as percepções dos professores no que diz respeito à dinâmica do curso, com relação: (i) ao trabalho em grupo e à reflexão; e (ii) ao trabalho orientado para a prática.

\section{Perspectivas dos professores sobre a abordagem curricular}

Analisamos, em seguida, as perspectivas dos professores sobre a abordagem curricular, nomeadamente no tocante à análise de materiais e de orientações curriculares, sobre o trabalho de caráter exploratório, no que se refere à forma de comunicação e ao uso de tarefas, e também sobre a realização de investigações estatísticas.

\footnotetext{
${ }^{3}$ Todos os professores são apresentados neste trabalho com nomes fictícios.
} 


\section{Análise de materiais didáticos e orientações curriculares}

A primeira sessão de trabalho incluiu a apresentação do módulo, bem como a análise de materiais didáticos e das orientações curriculares, com destaque para os Parâmetros Curriculares Nacionais (1998). Nesta fase, estava a decorrer a implementação da Base Nacional Comum Curricular (2018), que traz um olhar mais atento às atividades investigativas. A utilização das investigações estatísticas, referidas na BNCC como "projetos", foi um assunto amplamente abordado no decorrer das sessões.

Com atenção à realidade dos professores participantes, optamos por analisar os materiais didáticos que eles próprios utilizavam, nomeadamente os que são fornecidos pela Secretaria Municipal de Educação do Rio de Janeiro. Assim, puderam confrontar as orientações curriculares com os materiais fornecidos, bem como discutir coletivamente acerca da adequação das tarefas enunciadas com atenção aos aspectos que envolvem o desenvolvimento da literacia estatística. Apesar de ter sido tema de apenas uma sessão de formação, as discussões realizadas na análise dos materiais didáticos e das orientações curriculares foram mencionadas em diferentes momentos no decorrer das outras sessões.

No momento de apreciação das aprendizagens obtidas na primeira sessão, Dora, uma professora que atuava no primeiro ciclo do Ensino Fundamental, enuncia: "Eu sempre gostei de ter os PCNs em conta, mas sei que na correria do dia a dia essas orientações são meio que deixadas de lado e o foco acaba ficando nas apostilas e livros" (S1). A fala desta professora dá indícios do papel secundário que muitas vezes as orientações curriculares ocupam no contexto escolar, pelo que os materiais didáticos ganham destaque na prática profissional do professor. Este fato é realçado na observação de Manuel:

Eu confesso que só li os PCNs na graduação, e por isso nunca tinha prestado muita atenção no bloco de Tratamento de Dados ${ }^{4}$, porque na minha cabeça era só propor exercícios de gráficos e tabelas. Mas foi muito bom ver a ideia da literacia estatística de alguma forma no documento (Manuel, S1).

Para Manuel, rever as orientações curriculares ocasionou a percepção do real objetivo da inclusão da Estatística no currículo escolar. Isto é, o fato o fez atentar para a inclusão de aspectos relacionados ao desenvolvimento da literacia estatística, na medida em que os Parâmetros Curriculares Nacionais sugerem um trabalho relacionado a contextos reais que ocasionam o desenvolvimento de uma visão crítica ao lidar com dados.

Outro aspecto apontado pelos professores é a reflexão sobre o reduzido destaque que os conteúdos estatísticos recebem, geralmente, nos materiais. A este respeito, Carla afirma: "Acho que esta sessão serviu para perceber o quanto o assunto do Tratamento de Dados é esquecido nos materiais... Sempre fica por último e sempre tem pouquíssimos exercícios" (S1). A sua reflexão denuncia um incômodo com este fato, pelo que a análise mais minuciosa das orientações e dos materiais a faz perceber que o tema deveria ter um destaque muito maior. Deste modo, a professora conclui: "As estatísticas estão em tudo... Como dar tão pouco valor?" (S1).

\footnotetext{
${ }^{4}$ Na Base Nacional Comum Curricular, o bloco de Tratamento de Dados foi substituído pelo eixo temático denominado Probabilidade e Estatística.
} 
Esta sessão também gerou uma reflexão mais profunda acerca dos tipos de tarefas estatísticas a serem propostas aos alunos. Inicialmente, os professores apresentavam uma ideia de aplicação de tarefas estatísticas muito próxima da resolução de exercícios nos conteúdos matemáticos. O trabalho realizado levou-os a considerar a possibilidade de propor tarefas de outra natureza. Por exemplo, Jorge afirma: "É interessante porque eu nunca tinha pensado sobre as características de um exercício em Estatística" (S1). Reconhece, assim, que a prática de refletir acerca das potencialidades e particularidades de uma tarefa não é comum em sua prática.

\section{Abordagem exploratória das tarefas}

O trabalho realizado nas sessões de formação com tarefas de cunho exploratório levou os professores a demonstrar, inicialmente, alguma insegurança acerca deste tipo de abordagem. Este fato foi visível na realização de uma tarefa que envolvia um gráfico de barras com informações incompletas onde os alunos deveriam seguir uma série de instruções para adequar as informações corretamente. Neste contexto, André refere: "Isso é muito difícil... Acho que os meus alunos não conseguiriam responder" (André, S2). Marcos concordou: "É difícil mesmo. Os meus alunos precisariam de muito tempo para realizar uma atividade deste tipo. Eles ficariam dispersos e acho que com exercícios mais simples eles se prendem mais" (S2).

Entretanto, a comunicação estabelecida entre os professores no decorrer das sessões que privilegiaram as discussões e reflexões coletivas sobre a resolução das tarefas proporcionou a mudança da perspectiva dos professores. Isto é visível no comentário de André: "Agora, analisando, eu vejo que esse trabalho é bem mais proveitoso do que aqueles exercícios que vimos na outra aula. Na verdade, é mais trabalhoso porque o aluno precisa raciocinar, criar estratégias e ainda escrever... É desafiador" (André, S2). Este professor, que havia demonstrado anteriormente grande reserva diante da realização de tarefas desta natureza, foi capaz de perceber as suas potencialidades a partir do raciocínio a ser estabelecido, e reconheceu que elas poderiam propiciar o desenvolvimento de habilidades, tal como a comunicação deste raciocínio através da escrita.

Embora este momento tenha incluído apenas a resolução da tarefa pelos professores, é de notar que existe uma associação natural com a prática, pelo que, ao resolverem a tarefa, os professores procuram identificar as potencialidades para uma posterior aplicação em sala de aula. A motivação tornou-se mais profunda quando foram confrontados com exercícios voltados unicamente para cálculos, sem a exploração do raciocínio dos alunos, pelo que Marcos refere:

Estas atividades são diferentes daquelas que vimos nos materiais que analisamos na semana passada... Naqueles materiais algumas atividades só pediam cálculos ou uma interpretação simples de gráficos. É a primeira vez que vejo atividades de Estatística assim (Marcos, S2).

Na primeira sessão, referente à análise de orientações curriculares e de materiais didáticos, houve uma observação mais detalhada acerca das características das tarefas. Esta observação, tal como é apontado pelo comentário de Marcos, começa a ter uma complexidade maior, pelo que se percebe a diferença entre um exercício e uma tarefa de caráter exploratório. 
Na realização de tarefas de cariz exploratório foi possível o desenvolvimento de uma compreensão mais aprofundada acerca da Estatística. A este respeito, João afirma: "A forma como as atividades foram propostas me fez ter um conhecimento melhor do conteúdo. A atividade da tendência central me fez pensar sobre o significado da média e mediana, por exemplo" (João, S3). A tarefa em questão permitiu o uso de recursos tecnológicos, e os professores puderam perceber aspectos fundamentais das medidas de tendência central.

Associar a tecnologia à realização de tarefas estatísticas de caráter exploratório foi de grande valor, na perspectiva de Carla:

O uso da tecnologia nas atividades acrescentou bastante... Eu acredito que as construções feitas no curso são importantes para a compreensão dos alunos sobre os conceitos estatísticos. Apenas considero que eles precisariam de valores mais definidos, vários exemplos dirigidos para só então ficarem livres para observações (Carla, Q).

No balanço que os professores realizaram, houve destaque para a utilização dos recursos tecnológicos. Sobre isso, Beatriz afirma: "Me chamou atenção o trabalho no laboratório porque eu senti dificuldades... Sei que preciso estudar mais sobre isso. Trabalho mais com livros e materiais didáticos sem acesso à computação devido a trabalhar na escola pública" (Beatriz, S5). A professora assume as suas limitações no uso deste recurso e refere dificuldades em levar a tecnologia para a sua prática. Em contrapartida, assume a importância do uso da tecnologia no desenvolvimento do conhecimento da Estatística e da realização de uma investigação, afirmando que "com os programas no computador eu acho que dá pra construir os conhecimentos de um jeito mais dinâmico, sem se preocupar muito com os cálculos, e sim com o tratamento dos dados" (Beatriz, S5). Carla corrobora esta ideia ao referir que "não tem como separar a Estatística da tecnologia" (Carla, S5).

\section{Abordagem exploratória das tarefas}

$\mathrm{Na}$ quarta sessão foi realizada uma "mini-investigação estatística", ou seja, uma investigação de proporções reduzidas para que os professores pudessem vivenciar os processos do ciclo investigativo. Nesta mesma sessão foi planeada uma investigação a ser realizada com os alunos dos professores participantes, pelo que duas professoras - Beatriz e Carla - se dispuseram a desenvolver a atividade com suas turmas e, na quinta e última sessão, puderam levar contribuições acerca das potencialidades e limitações relativas à execução de uma tarefa de cunho investigativo. Todos os professores participantes apontaram que não tinham experimentado atividades análogas na formação inicial. Beatriz, uma professora experiente que atua no Ensino Fundamental, fez a seguinte observação:

A minha graduação não explorou bem a Estatística. Este trabalho (de investigação) só foi aparecer neste curso e eu gostei muito. Eu já tinha um conhecimento dentro do Ensino Fundamental por causa dos PCNs e no curso eu percebi que era mais profundo com as investigações. Achei o curso muito proveitoso. Fazer com que os alunos façam investigações... Isso deveria fazer parte da graduação (formação inicial). Eu achei muito legal ver a riqueza de informações na hora da coleta. Foi interessante ver que a Estatística não caminha sem a investigação (Beatriz, S4). 
A professora relatou que "já apresentava, em sua prática, uma abordagem da Matemática voltada para os contextos sociais dos alunos". Além disso, demonstrou grande interesse no decorrer da mini-investigação, de modo a considerar aquela uma atividade essencial para o desenvolvimento do conhecimento estatístico. As lacunas existentes na formação inicial, aliadas à escassez de materiais de apoio para a abordagem da Estatística, não possibilitavam uma abordagem mais profunda do conteúdo em sala de aula. Entretanto, experimentar o ciclo investigativo na formação - e posteriormente com a sua turma - foi fundamental para que houvesse uma ressignificação do ensino da Estatística.

Ainda na perspectiva de mudança de paradigma acerca da abordagem da Estatística, Victor afirma: "A atividade me fez perceber que é possível desenvolver um senso de pesquisa, observação e análise dos dados" (Victor, Q). Bernardo, por sua vez, afirma que as investigações estatísticas promovem uma aprendizagem ativa dos conceitos estatísticos, e mostrou perceber que esta atividade proporciona um trabalho favorável para 0 desenvolvimento da literacia estatística:

Eu vi tarefas que não são monótonas, tipo "arme e efetue". Percebo uma matemática investigativa, para que os alunos sejam mais críticos...

Acho que as investigações fazem com que os alunos criem autonomia para encontrarem respostas para as suas perguntas. Além da possibilidade de utilizarem temas que são interessantes para eles (Bernardo, Q).

O professor ainda refere a necessidade de associar as investigações estatísticas ao contexto real dos alunos, de modo a dar mais significado aos conceitos estatísticos.

\section{Perspectivas dos professores sobre a dinâmica da formação}

Analisamos, em seguida, as perspectivas dos professores sobre a dinâmica da formação, nomeadamente no que diz respeito ao trabalho em grupo e a reflexão coletiva e a orientação para a prática.

\section{Trabalho em grupo e a reflexão}

Um aspecto presente em todo o desenvolvimento da formação foi a articulação de trabalhos em grupo e a constante reflexão coletiva de cada tema trabalhado. Os participantes creditaram diferentes aprendizagens a esta dinâmica formativa. Por exemplo, Márcio, se referindo às suas experiências de formação anteriores, afirma: "É a primeira vez, durante uma aula, que consigo saber como é exatamente a vivência dos meus colegas. Geralmente focamos muito em estudar os conteúdos de Matemática, mas conversamos muito pouco sobre a prática" (Márcio, S3).

A resolução de tarefas e a discussão de diferentes conceitos estatísticos tiveram lugar no decorrer das sessões, pelo que os professores compartilharam seus conhecimentos uns com os outros de modo a contribuir para as aprendizagens. Neste sentido, Bernardo afirma: "As discussões em cada sessão foram muito boas... Aprendemos muito uns com os outros" (Bernardo, S5). Na apreciação do trabalho desenvolvido, existiu ainda uma referência clara 
da relação entre o trabalho coletivo e questões associadas à prática profissional. Ao relatarem suas experiências com o ensino dos conceitos estatísticos e suas posições acerca de situações associadas à prática, os professores, no decorrer das sessões, reconheceram o ambiente formativo como um lugar confortável para, inclusive, relatarem os seus receios e inseguranças. A este respeito, por exemplo, Beatriz refere: "O trabalho em conjunto foi fundamental para ver que as minhas inseguranças não são só minhas" (Beatriz, S5).

\section{Orientação para a prática}

A formadora atuava também em turmas do Ensino Fundamental e levou documentos que os seus alunos produziram para o foco das discussões. $O$ uso destes materiais revelouse muito frutuoso. A este respeito, Victor afirma: "Ver as respostas de alunos que têm perfis parecidos com os dos meus alunos me faz pensar que é só dar um tempo maior para eles resolverem... E tem que dar apoio, também. Foi muito bom refletir sobre isso" (Victor, S2). Quanto ao fato de as respostas dos alunos terem sido referentes a tarefas de natureza exploratória, Gustavo complementa: "Ver a participação deles em tarefas tão diferentes das que são habituais nos encoraja um pouco a fazer coisas diferentes" (Gustavo, S2).

Conforme referido, na quarta sessão foi realizada uma mini-investigação estatística e o planejamento de uma investigação a empreender com alunos do Ensino Fundamental. Na quinta sessão foi feita uma discussão sobre os principais aspectos da realização destas investigações. Estes dois momentos trouxeram importantes reflexões acerca da prática. Por exemplo, Victor afirma:

Eu achei muito interessante a ideia de fazer investigações numa turma... Ajuda a gente a ter um entendimento maior, os dados têm mais qualidade. Os livros didáticos falam em gráficos, mas é muito superficial. Se os professores ajudassem os alunos a desenvolver o raciocínio e interpretar seria mais produtivo. Achei legal a ideia de trabalhar numa turma... Eles podem vivenciar o que acontece em pesquisas tipo 0 Datafolha... Acho que é uma coisa que todo o mundo vive. Inclusive as crianças, né. (Victor, S5)

Vitor compara as propostas dos livros didáticos à possibilidade de um trabalho mais profundo acerca dos conceitos estatísticos, de modo a desenvolver diferentes habilidades. $\bigcirc$ professor é capaz de perceber que uma investigação estatística, mesmo que não tenha o rigor e complexidade do trabalho de um estatístico, é capaz de promover a aproximação dos alunos a um contexto real de aplicação destes conceitos.

Beatriz, uma das professoras que realizou uma investigação com a sua turma, demonstra que esta prática ocasionou um impacto na sua forma de lecionar os conceitos estatísticos: "Na investigação, eles entraram num consenso para ver quais eram as necessidades da escola e levantamos uma questão muito bacana sobre saneamento básico junto com a Estatística. Eu já tinha essa visão de transformar os alunos em pessoas mais críticas e com o curso fiquei com essa visão mais forte ainda... Então, eu acho que ter essa visão crítica é muito importante para o futuro... Hoje eu trabalho assim e não vou parar" (Beatriz, E). Deste modo, a professora apresenta uma prática que relaciona o conteúdo estatístico aos contextos reais dos seus alunos. A professora ainda demonstra acreditar que este tipo de prática é capaz de desenvolver a criticidade dos alunos. Deste modo, a 
experiência formativa com as investigações contribuiu para ressignificar a sua ação em sala de aula.

Na fase da realização de investigações estatísticas, Carla se dispôs a realizar esta atividade com os seus alunos e levar as suas considerações para o grupo. Apesar de ser uma professora muito experiente e comprometida, demonstrava muito receio em realizar atividades desta natureza, afirmando: "As minhas turmas são muito lotadas. São mais de 40 alunos. A chance de perder o controle é muito grande." (Carla, S5). Após a realização da experiência, a professora detalhou as potencialidades e as limitações - que tinham uma relação maior com a logística. Apesar dos receios, afirmou: "Eu vi que é muito possível. O mais legal é que os meus alunos ficaram muito envolvidos com a atividade." (Carla, S5).

Num momento de balanço acerca do curso, a valorização destes dois elementos foi bastante evidente. Acerca do uso dos contextos reais da atividade docente, Fábio afirma:

Esse módulo foi diferente dos outros, porque além de ver a parte dos conteúdos, você [formadora] também trouxe experiências da prática em sala de aula. Essa abordagem foi interessante porque ajudou a gente a ter um pouco mais de ideia de como o aluno enxerga o assunto, como eles podem desenvolver os conhecimentos e com essas informaç̃es a gente pode até direcionar a aprendizagem de uma forma melhor para eles (Fábio, S5).

Deste modo, Fábio demonstra valorizar a importância de compreender o modo como os alunos raciocinam para a condução da sua prática docente.

Marcos também faz esta referência, quando afirma:

O que eu achei mais importante é que me ajudou a ver por outro modo como as crianças pensam e como elas sentem dificuldades e como nós, professores, podemos nos adequar a elas fazendo com que nos moldemos para que o ensino seja o mais proveitoso possível. Eu nunca tive aulas assim na graduação, infelizmente, e é muito importante trabalhar isso na formação. É importante que o graduando comece a pensar no aluno desde cedo, e não que ele fique preocupado só com as provas que tem que fazer. (Marcos, S5)

A expressão de Marcos vem de encontro à ideia de que o importante é a compreensão que os alunos têm dos conceitos e não o número de respostas certas ou erradas em provas de avaliação.

\section{Conclusão}

Uma das características principais desta experiência de formação consiste em enfatizar uma abordagem exploratória da Estatística (ESTEVAM ET AL., 2017; PONTE, 2005). Esta valorização destaca-se no trabalho em torno das tarefas, das investigações estatísticas e da comunicação estabelecida na sala de aula. Os professores participantes nesta experiência de formação valorizaram o tipo de tarefa apresentado, com o destaque para as investigações estatísticas. Em muitos momentos, tal como em Estevam e Cyrino (2017), refletiram sobre as tarefas realizadas na formação de modo a projetarem uma aplicação em sala de aula. Isto é, em diversos momentos os professores ressaltaram a resolução das tarefas e o 
estabelecimento da comunicação como aspectos a serem incorporados em sua própria prática.

O ensino da Estatística associado às investigações ainda não possui ampla divulgação, pelo que a generalidade dos professores não teve experiências de formação centradas no ciclo investigativo da Estatística (HENRIQUES; OLIVEIRA, 2013). Os relatos dos professores participantes referiram como a primeira vez que participaram de uma atividade desta natureza. Com as investigações e as tarefas de cariz exploratório, perceberam que um estudo centrado apenas em cálculos não possibilita o desenvolvimento da literacia estatística (FRANKLIN ET AL., 2005). Passaram a destacar as potencialidades das investigações na aprendizagem de conceitos estatísticos e a aplicação aos contextos reais.

Os professores também destacaram a dinâmica da formação, que os levou a considerar situações autênticas de sala de aula. Na sua perspectiva, a análise das respostas e erros dos alunos teve grande importância, contribuindo para que eles pudessem construir novos patamares de conhecimento. A reflexão conjunta também foi um elemento de destaque para os professores. A partilha de experiências e compreensões foi essencial para a mudança de paradigma quanto ao trabalho em Estatística em sala de aula, para uma abordagem de cunho exploratório. O encorajamento nas sessões de formação para a realização de discussões (SMITH, 2001), para que os professores tenham uma aprendizagem significativa dos conceitos e questões relacionados com o ensino e aprendizagem da Estatística, revelou-se frutuoso. Deste modo, o balanço realizado pelos professores confirma a necessidade de promover formações que sejam capazes de articular uma perspectiva curricular inovadora, como é o caso da promoção da literacia estatística através de uma abordagem exploratória, com a valorização de experiências, discussões e reflexões baseadas na prática docente.

\section{Referências}

BATANERO, C. Estadística y didáctica de la matemática: Relaciones, problemas y aportaciones mutuas. En C. Penalva, G. Torregrosa \& J. Valls (Eds.), Aportaciones de la didáctica de la matemática a diferentes perfiles profesionales. Universidad de Alicante, p. 95120,2002

BEN-ZVI, D.; GARFIELD, J. B. (Eds.). The challenge of developing statistical literacy, reasoning, and thinking. Dordrecht: Kluwer, 2004.

BRASIL. Parâmetros Curriculares Nacionais: Matemática $\left(1^{\circ}\right.$ e $2^{\circ}$ ciclos do ensino fundamental). Brasília: MEC Ministério da Educação. Secretaria de Educação Fundamental, 1997.

BRASIL. Parâmetros Curriculares Nacionais: Matemática $\left(3^{\circ}\right.$ e $4^{\circ}$ ciclos do ensino fundamental). Brasília: MEC, Ministério da Educação. Secretaria de Educação Fundamental, 1998.

BURRILL, G., \& BIEHLER, R. Fundamental statistical ideas in the school curriculum and in training teachers. In C. Batanero, G. Burrill \& C. Reading (Eds.), Teaching statistics in school mathematics: Challenges for teaching and teacher education (A Joint ICMI/IASE Study) (pp. 57-69). New York, NY: Springer, 2011. 
COBB, P. ET AL. Design experiments in educational research. Educational Researcher. Washington, v. 32, n. 1, p. 9-13, 2003.

COSTA, A.; NACARATO, A. M. A estocástica na formação do professor de matemática: Percepções de professores e de formadores. Bolema, Rio Claro (SP), v. 24, n. 39, p. 367-386, 2011.

COUTINHO, C. D.; SPINA, G. A estatística nos livros didáticos de ensino médio. Ensino da Matemática em Debate, São Paulo (SP), v. 2, n. 2, 2015.

DAY, C. Desenvolvimento profissional de professores: os desafios da aprendizagem permanente. Porto: Porto Editora, 2001.

ERICKSON, F. Qualitative methods in research on teaching. In M. C. Wittrock (Ed.), Handbook of Research on Teaching, p. 119-161. New York, NY: Macmillan, 1986.

ESTEVAM ET AL. Análise de vídeos de aula na promoção de reflexões sobre o ensino exploratório de Estatística em uma comunidade de professores. Quadrante, Lisboa, v. 26, n. 1, p. 145-169, 2017.

FRANKLIN ET AL. Guidelines for assessment and instruction in statistics education (GAISE) Report. Alexandria, VA: American Statistical Association, 2005.

GREEN, J.; BLANKENSHIP, E. Primarily Statistics: Developing an Introductory Statistics Course for Pre-service Elementary Teachers. Journal of Statistics Education, London, v. 21. n. 3, 2013.

HEATON, R. M.; MICKELSON, W. T. The learning and teaching of statistical investigation in teaching and teacher education. Journal of Mathematics Teacher Education, Rotterdam, Netherlands, v. 5. n. 1, p. 35-59, 2002.

LOPES, C. E. Educação Estatística no Curso de Licenciatura em Matemática. Bolema, Rio Claro (SP), v. 27, n. 47, p. 901-915, dez. 2013.

MARTINS, M. E. G.; PONTE, J. P. Organização e tratamento de dados. Lisboa: DGIDC, 2007.

NCTM. Curriculum and evaluation standards for school mathematics. NCTM: Reston VA, 1989.

PONTE ET AL. Perspetivas teóricas no estudo das práticas profissionais dos professores de matemática. In A. P. Canavarro, L. Santos, A. M. Boavida, H. Oliveira, L. Menezes \& S. Carreira (Eds.), Práticas de ensino da Matemática: Atas do Encontro de Investigação em Educação Matemática. p. 267-279. Lisboa: SPIEM, 2012.

PONTE, J. P. ET AL. Formação de professores dos primeiros anos em articulação com o contexto de prática de ensino de Matemática. RELIME, Cidade de México, v. 13, n. 1, p. 7194, 2017.

PONTE, J. P. Gestão curricular em Matemática. In GTI (Ed.), O professor e o desenvolvimento curricular. p. 11-34. Lisboa: APM, 2005.

PONTE, J. P. Preparing teachers to meet the challenges of statistics education. In C. Batanero, G. Burrill \& C. Reading (Eds.), Teaching statistics in school mathematics: Challenges for teaching and teacher education (A Joint ICMI/IASE Study). p. 299-309. NewYork, NY: Springer. (ISBN 978-94- 007-1130-3, Hardcover), 2011. 
SANTOS, R. M., \& BRANCHES, M. V. Problemas identificados em gráficos estatísticos publicados nos meios de comunicação. Revista de Educação em Ciências e Matemática. Amazônia. v.15, n. 33. p.201-218, 2019.

SMITH, M. S. Practice-based professional development for teachers of mathematics. Reston, VA: NCTM, 2001.

STEIN, M. K. ET AL. Orchestrating productive mathematical discussions: Five practices for helping teachers move beyond show and tell. Mathematical Thinking and Learning. London, v. 10, p. 313-340, 2008.

STEIN, M. K., \& SMITH, M. S. Mathematical tasks as a framework for reflection: From research to practice. Mathematics Teaching in the Middle School. Reston, VA, EUA, v. 3, n. 4, p. 268275, 1998. 